\title{
Rhythmic vowel deletion in OT: Syncope in Latin
}

HAIKE JACOBS

\section{Abstract}

This paper analyses the optional process of vowel deletion in the historical phonology of Latin. It is argued that a minimal modification of Prince and Smolensky's (1993) account of Latin stress allows for a uniform characterization of the context of all cases of syncope (the weak position of a foot), a result that cannot be achieved in a Hayes (1995) rule-based account.

The OT-analysis of the syncope process itself, however, is less straightforward, as the actual output of syncope renders the prosodic generalizations of the language opaque. It will be shown that it is impossible to account for vowel deletion in a fully parallel fashion, that is, with one and the same constraint hierarchy. The opacity of syncope is discussed in some detail and it will be argued that several alternatives to a derivational OT analysis are unable to provide an adequate account. Finally, it is shown that if stress is lexically present the opacity problem can be circumvented.

\section{Introduction}

Rhythmic vowel deletion, in which iterative feet are identified as the context of deletion, and where that context arises only momentarily in the derivation, but is lost in the output due to syncope and resyllabification results in opacity and, as such, poses a challenge for Optimality Theory (henceforth OT). Kager (1997) distinguishes two types of rhythmic vowel deletion: gradient and categorical. Gradient rhythmic vowel deletion, as in Macushi Carib, preserves the syllabicity of the 'deleted' vowel and thus also preserves the foot-based context in the output. Given that the context is recoverable from the output, gradient vowel deletion involves no opacity. Categorical rhythmic vowel deletion, as in South-eastern Tepehuan, is phonologically complete and destroys the syllab- 
icity of the deleted vowel. Whereas categorical vowel deletion is governed by phonotactic considerations, gradient vowel deletion is not, because in the latter case the syllabicity of the 'deleted' vowel is preserved. Given that there is no surface rhythmic pattern present by which categorical deletion can be conditioned, Kager argues that this type of vowel deletion cannot be due or be conditioned by iterative feet, but rather has to be due to the minimization of the number of unparsed syllables, which removes the opacity problem by making the analysis fully surface-based.

In this paper, we will discuss the syncope patterns that occurred in the historical phonology of Latin in the light of the typological perspective argued for by Kager. It will be demonstrated that syncope did not lead to the minimization of the number of unparsed syllables. Cases of syncope in initial LL sequences, such as sŏlĭdus becoming sŏldus, clearly show that exhaustive parsing (the minimization of the number of unstressed syllables) cannot be the motivating force behind vowel deletion. The two light syllables before and the remaining heavy syllable after deletion are both perfect feet. It is therefore that Latin vowel deletion cannot be considered as categorical deletion. On the other hand, Latin syncope cannot be regarded as gradient vowel deletion either. If it were, one would expect phonotactic constraints to be irrelevant, which was certainly not the case in Latin.

This paper purports to develop an analysis of rhythmic vowel deletion in Latin as both categorical and as foot-based. The paper is organized as follows. Section 2 presents the analysis of Latin stress proposed by Prince and Smolensky (1993). After the presentation of the main facts of syncope in the phonology of Latin, Section 3 shows that a minimal modification of the Prince and Smolensky OT-account is able to identify in a uniform way the context of all syncope cases: the weak position of a foot. After that, Section 4 discusses and shows why a rule-based account, contrary to an OT-account, is unable to produce the same result. In Section 5, the OT-analysis of the syncope process is provided. It will be shown that the facts of Latin simply cannot be analyzed by using one, single constraint hierarchy. In Section 6 we return to the opacity problem and discuss why several alternative accounts to a derivational OT analysis are unable to provide an adequate account. Finally, we will show that, in addition to a derivational analysis where evaluation takes place in levels, there is another way to circumvent the opacity problem, that is, by lexically representing stress.

\section{Latin stress}

In this section we will briefly discuss the way in which Prince and Snolensky (1993) have analysed stress in Latin. The basic facts are well known. Main stress in words of more than two syllables is on the penultimate syllable if that 
syllable is heavy, if not, main stress is on the antepenultimate syllable. In (1) we have provided some examples together with the foot structure they would get if analysed in a rule-based fashion with a moraic trochee (cf. Hayes 1995). The last syllable is made extrametrical (indicated by angled brackets) prior to the assignment of a moraic trochee.

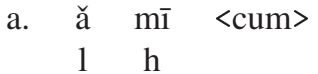
(x)
'friend'
b. lā mù <nă>
$\mathrm{h}$
'plate'
(x)
c. sŏ $l \breve{1}<$ dus>
$1 \quad 1$
(x .)
'solid'
d. $\quad \bar{a} \quad \breve{r} \quad<$ dus $>$
‘dry'

(x)

The OT-account proposed by Prince and Smolensky (1993) makes use of the constraints listed in (2), where they have been divided in constraints responsible for foot form, foot position, and constraints guaranteeing quantity-sensitivity of main stress.

(2)

a. Foot form

FTBIN: $\quad$ Feet are binary

RHTYPE (T): $\quad$ Rhythm is trochaic

$*(\underline{H} \mathrm{~L})$ : $\quad$ No uneven trochees

b. Foot position

Align Hd-Foot,R, PrWd,R (H/R): Main stress is final

Align Hd-Foot,L, PrWd,L (H/L): Main stress is initial

Align PrWd, R, Ft, R (W/R): $\quad$ Word ends with a foot

Align PrWd, L, Ft, L (W/L): $\quad$ Word starts with a foot

NonFinality $(\underline{F}, \underline{\sigma})($ NONF $) \quad$ The foot with main stress is

PARSe- $\sigma$ :

not final

Clash:

Parse syllables into feet

Avoid a clash with main

stress

c. Quantity-sensitivity

WEIGHT-TO-STRESS (WSP): Heavy syllables are stressed

WEIGHT-B Y-POSITION (WBP): Coda consonants are moraic

MAX- $\mu$-IO/PARSE- $\mu$ (MAX- $\mu)$ : Underlying mora must be parsed 
In the Tableaux that follow we have not indicated all the constraints, but only those relevant for the evaluation of the particular forms involved. For instance, we have not indicated the constraint RHTYPE (T) according to which the rhythm is trochaic, but simply assume it is sufficiently high ranked to exclude any iambic feet. Also, the Alignment constraints in (2b), which in a full ranking will have the following order: W/R $>W / L$ and $H / R>H / L$ are in most of the tableaux represented only with the first, higher ranked, constraint of each pair. Furthermore, we have collapsed, for expository reasons the constraints listed in (2c) as one single constraint QS. The ranking assumed by Prince and Smolensky produces the analysis illustrated in Tableaux (3)-(5), where main stress is indicated by underscoring the syllable carrying it.

(3)

\begin{tabular}{|c|c|c|c|c|c|c|}
\hline$/ \mathrm{HLL} /$ & $*(\mathrm{HL})$ & NONF & H/R & W/R & QS & PARSE- $\sigma$ \\
\hline lāmı̆nă & & & & & & \\
\hline$(\underline{\mathrm{H}})(\mathrm{LL})$ & & & $\sigma \sigma$ & & & \\
\hline$(\underline{\mathrm{H}}) \mathrm{LL}$ & & & $\sigma \sigma$ & $\sigma ! \sigma$ & & $* *$ \\
\hline$(\underline{\mathrm{H}}) \mathrm{L}$ & $* !$ & & $\sigma$ & $\sigma$ & & $*$ \\
\hline$(\mathrm{H})(\underline{\mathrm{L}})$ & & $* !$ & & & & \\
\hline
\end{tabular}

(4)

\begin{tabular}{|c|c|c|c|c|c|c|}
\hline$/$ LLH/ & $*(\mathrm{HL})$ & NONF & $\mathrm{H} / \mathrm{R}$ & $\mathrm{W} / \mathrm{R}$ & $\mathrm{QS}$ & PARSE- $\sigma$ \\
\hline sŏlĭdus & & & & & & \\
\hline$(\mathrm{LL})(\underline{\mathrm{H}})$ & & $* !$ & & & & \\
\hline$(\underline{\mathrm{LL}}) \mathrm{H}$ & & & $\sigma$ & $\sigma !$ & $*$ & $*$ \\
\hline$\underline{\mathrm{LL}})(\mathrm{H})$ & & & $\sigma$ & & & \\
\hline $\mathrm{L}(\underline{\mathrm{L} H})$ & & $* !$ & & & $*$ & $*$ \\
\hline
\end{tabular}

(5)

\begin{tabular}{|c|c|c|c|c|c|c|}
\hline /HLH/ & $*(\mathrm{HL})$ & NONF & H/R & W/R & QS & PARSE- $\sigma$ \\
\hline ărĭdus & & & & & & \\
\hline$(\underline{\mathrm{H}}) \mathrm{L}(\mathrm{H})$ & & & $\sigma \sigma$ & & & $*$ \\
\hline$(\underline{\mathrm{H}}) \mathrm{LH}$ & & & $\sigma \sigma$ & $\sigma ! \sigma$ & $*$ & $* *$ \\
\hline$(\underline{\mathrm{H}})(\mathrm{LH})$ & & & $\sigma \sigma$ & & $* !$ & \\
\hline$(\underline{\mathrm{H}} \mathrm{L}) \mathrm{H}$ & $* !$ & & $\sigma$ & $\sigma$ & $*$ & $*$ \\
\hline
\end{tabular}

Words like lāmı̆nă 'plate' illustrate (3), sŏlı̆dus 'solid (adj.)', sŏlŭdum 'the sum (subst.)' călı̆dus 'warm, hot' and vı̆r̆dis 'green' (4) and words like ārŭdus 'dry', or porrügō 'to stretch out' (5).

Below, again for expository reasons, we have repeated for each of these word types the optimal prosodic analysis.

$(\underline{\mathrm{H}})(\mathrm{LL}) \quad$ for words of the type lāmı̆nă

(4) $\quad(\underline{\mathrm{LL}})(\mathrm{H})$

for words of the type sŏlı̆dus

(5) $\quad(\underline{\mathrm{H}}) \mathrm{L}(\mathrm{H})$

for words of the type $\bar{a} r \grave{r} d u s$ 
In this section, we have briefly recapitulated Prince and Smolensky's analysis of Latin stress. In the next section, we will turn to syncope and show that a minimal modification of the OT-account is able to identify in a uniform way the context of all syncope cases: the weak position of a foot. A short word of caution is in order. Prince and Smolensky have defended their analysis not on the basis of the Latin syncope facts, but on cases of shortening. We will not go into that aspect here, but refer the reader to Jacobs (2003).

\section{Foot-based vowel deletion in Latin}

\subsection{The basic facts}

From Early Classical Latin (starting with Plautus in the 3rd century BC) until Late Latin (in the 3rd century AD)) syncope has been an optional process in the language. It was sensitive to syllable structure, taking place mainly, but not exclusively, between a sonorant ( $1, \mathrm{r}$, nasal) and a plosive.

Mester (1992), assuming a moraic trochee analysis of Latin stress as in (1) above, argues that syncope only takes place in cases of a so-called 'trapped' syllable, that is, a syllable that is not metrified, such as, for instance, the second syllable in (5) (or (1d)), as in ārüdus and porrĭgō. Syncope is considered to be a means of fully metrifying the syllables of a word. Seen as such, it is predicted to produce ardus and porgo, but not caldus, soldus, virdis, or lamna, that is, syncope should not take place in words of the type (3) or (4). ${ }^{1}$

Mester restricts himself to Early Classical Latin (the Latin of Plautus or Plautinian Latin (Plautus (244-184 BC)) and Classical Latin, and cites, with respect to syncope, Lindsay $(1894,173)$ who states that syncope "seems, during the Republic and early Empire, to occur only when the accented vowel is long." Mester then concludes: "as a process predominantly affecting post-tonic light syllables stranded between heavy syllables, it receives a natural interpretation in a strictly bimoraic theory as a way of resolving trapping situations." However, Lindsay's remark continues as follows: "though we find it [syncope] in the period of the Early literature after a shortened vowel in words of four or more syllables where three short syllables followed each other before the final syllable." Some examples are balneum for bălı̆nĕum 'bath' and optumus

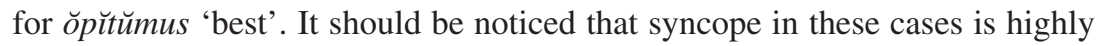
problematic and poses a conundrum, not only for Mester's account, but for any analysis, if regarded from the point of view of the Classical Latin stress pattern: it seems as if the vowel (the third one from the right word edge) that has main stress is deleted. We will return to these cases in Section 3.3.

1. Mester assumes that after main stress assignment in words such as (1b), the two remaining light syllables are grouped into a single foot as well. 
Mester gives only one example of syncope in words of the type (3) and (4): valdē for vălı̆de 'very, strong' and says: "This kind of syncope began in Vulgar Latin and became fully general in Late Latin. The crucial observation is that such examples constitute a small minority in the literary language." Late Latin syncope is analysed differently, but crucially after quantity distinctions among vowels had been lost. The question of course is whether Latin syncope, prior to the loss of vowel quantity distinctions, was really restricted to type (5) words, that is, to trapped syllables. In this respect Allen (1973: 152) notes: "In any case some such effects are in fact to be observed even in connexion with the classical accent, as, e.g., in disciplinna (besides disč̆pŭlus); moreover, the conservatism of normative spelling may well conceal instances of syncope or lead us to ascribe them to a later period; there were probably many 'popular' forms of the type caldus (<calidus) [...], which have simply gone unrecorded." Furthermore, we know from Quintilian that the first emperor, Octavianus Augustus, considered the pronunciation călüdus instead of caldus as affected. ${ }^{2}$

The next emperor, to stay in the early Empire, Tiberius, had as nickname Caldius (heathed by wine). Still earlier we find domnus and lamna for d̆̌mŭnus 'lord' and lämı̆nă in Plautus and Horatius, soldus and virdis for sŏlı̆dus and

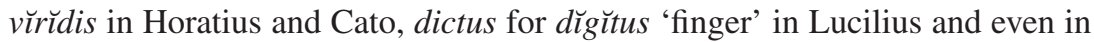
official law texts, such as Caesars Lex Municipalis (45 BC), we find soldum for sŏlŭdum (all examples are taken from Lindsay (1894)). So, in conclusion, syncope did take place or could take place (given the optionality of the process) in all word types (3), (4) and (5). In all these words the second vowel was subject to syncope: lamna, soldus, and ardus.

For both Mester and Prince and Smolensky's analysis this is a problem. Sometimes the syncopated vowel is in the strong position of the foot (in (3)), sometimes it is a trapped vowel (in (5)), and sometimes it is in the weak position of the foot (in (4)).

In the passage directly preceding the one cited by Mester, Lindsay discusses pre-tonic syncope, syncope before main stress. Mester assumes a moraic trochee for secondary stress assigned at the left word edge and the obvious prediction again is that syncope can apply in an HL sequence, but not in an LL sequence followed by main stress, given that only in HL there is a trapped syllable. However, we find syncope in both environments. Examples of syncope in HL are ardēre 'to burn' for *ārüdēre and ardōrem 'fire' for *ārĭdorem (cf.

2. "Sed Augustus quoque in epistolis ad C. Caesarem scriptis emendat, quod is calidum dicere quam caldum malit, non quia id non sit Latinum sed quia sit odiosum et ut ipse Graeco verbo

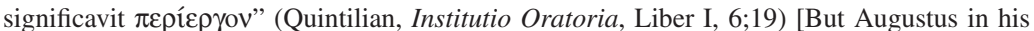
letters to C. Caesar reproached him that he preferred to say calidum rather than caldum, not that this were not Latin, but that this is ugly and as he himself in Greek has put it: affected, $\mathrm{HJ}]$. 
aridus). Examples of syncope in LL are calfacere for călĕfácere 'to heath' and caldarius for călı̆darius (cella caldaria) 'room for hot baths'. Also, we know from Quintilian (I. 6. 21) that in his time the normal pronunciation was calfacere and olfacere 'to smell' and not calefacere or olefacere. Mester adds in a footnote (1994: 39) that they "mostly also occur in trapping situations", but Lindsay, on the other hand, gives just some more examples of syncope in LL than in HL. To mention just a few more examples of syncope in pre-tonic LL sequences: officina 'working place' for orp rfficina (still in that form in Plautus), Aprīlis 'April' for ăpĕrīlis and aprīcus 'sunny' for ăpĕrīcus, audēre 'to dare' for *ăv̌̆dère (cf. ăvı̆dus), figlina 'pottery' for fĭgŭlīna.

In conclusion, then, a re-examination of the facts shows that syncope did take place or could take place in all word types (3), (4) and (5). In all these words, the second vowel was subject to syncope. Furthermore, in pre-tonic sequences it affected LL and HL sequences at least equally.

\subsection{Towards a unified account of Latin syncope}

In this section, we will show that a minimal modification of the OT-account is able to identify in a uniform way the context of all syncope cases: the weak position of a foot. We first modify the constraint NONFINALITY, as in (6), in such a way that every foot in final position, irrespective of whether it has main stress or not, violates it.

$$
\text { NonFinality (NONF): A foot may not be final }{ }^{3}
$$

Furthermore, we assume that the constraint $*(\mathrm{HL})$ is not an undominated constraint (as in Prince and Smolensky (1993)), but that it can be violated. In Tableaux (7)-(9), we illustrate the consequences of these two minimal modifications with the possible candidates for the by now familiar word types (3)-(5).

(7)

\begin{tabular}{|c|c|c|c|c|c|c|}
\hline$/$ HLL/ & NONF & H/R & W/R & QS & PARSE- $\sigma$ & $*(\mathrm{HL})$ \\
\hline lāmĭnă & & & & & & \\
\hline$(\underline{\mathrm{H}})(\mathrm{LL})$ & $* !$ & $\sigma \sigma$ & & & & \\
\hline$(\underline{\mathrm{H}}) \mathrm{LL}$ & & $\sigma \sigma !$ & $\sigma \sigma$ & & $* *$ & \\
\hline$\underline{\mathrm{H} L}) \mathrm{L}$ & & $\sigma$ & $\sigma$ & & $*$ & $*$ \\
\hline$(\mathrm{H})(\underline{\mathrm{LL}})$ & $* !$ & & & & & \\
\hline
\end{tabular}

3. We refer the reader to Jacobs (1999), where it is shown that the modification of NONFINALITY is independently required to avoid systematic quaternary stress systems. 
(8)

\begin{tabular}{|c|c|c|c|c|c|c|c|}
\hline & /LLH/ & NONF & $\mathrm{H} / \mathrm{R}$ & $\mathrm{W} / \mathrm{R}$ & QS & PARSE- $\sigma$ & $*(\mathrm{HL})$ \\
\hline \multicolumn{8}{|c|}{ sŏlǐdus } \\
\hline & $(\mathrm{LL})(\underline{\mathrm{H}})$ & $* !$ & & & & & \\
\hline & $(\underline{\mathrm{LL}})(\mathrm{H})$ & $* !$ & $\sigma$ & & & & \\
\hline 18 & (LL)H & & $\sigma$ & $\sigma$ & * & * & \\
\hline & $\mathrm{L}(\underline{\mathrm{LH}})$ & $* !$ & & & * & * & \\
\hline & /HLH/ & NONF & $\mathrm{H} / \mathrm{R}$ & $\mathrm{W} / \mathrm{R}$ & QS & PARSE- $\sigma$ & $*(\mathrm{HL})$ \\
\hline \multicolumn{8}{|c|}{ ārĭdus } \\
\hline & $(\underline{\mathrm{H}}) \mathrm{L}(\mathrm{H})$ & $* !$ & $\sigma \sigma$ & & & * & \\
\hline & $\underline{(\mathrm{H})} \mathrm{LH}$ & & $\sigma \sigma !$ & $\sigma \sigma$ & $*$ & $* *$ & \\
\hline & $(\underline{\mathrm{H}})(\mathrm{LH})$ & $* !$ & $\sigma \sigma$ & & $*$ & & \\
\hline 嘫 & (느)H & & $\sigma$ & $\sigma$ & $*$ & * & $*$ \\
\hline
\end{tabular}

It is clear that the vowel that is in principle subject to syncope is now always in the same structural position: the weak position of a foot, as repeated below for the optimal output candidates in the Tableaux above.

(7) $\quad$ (HL) L for words of the type lämŭnă

(8) $\quad(\underline{L} L) H \quad$ for words of the type sŏlı̆dus

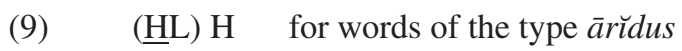

We also have the same structural context for pre-tonic syncope: both HL followed by main stress (type *ärüdōrem > ardōrem) and LL followed by main stress (type călŭdária > caldária) form a foot, as illustrated in (10) and (11). Secondary stress is indicated by boldface.

\begin{tabular}{|l|c|c|c|c|c|c|}
\hline /HL $\underline{\sigma} /$ & NONF & H/R & W/R & QS & PARSE- $\sigma$ & $*(\mathrm{HL})$ \\
\hline arrúrem & & & & & & \\
\hline HL $\underline{\sigma}$ & & & & & $* * !$ & \\
\hline$(\mathbf{H}) \underline{\sigma} \underline{\sigma}$ & & & & & $* !$ & \\
\hline$($ HL) $\underline{\sigma}$ & & & & & & $*$ \\
\hline \hline /LL $\underline{\sigma} /$ & NONF & H/R & W/R & QS & PARSE- $\sigma$ & $*(\mathrm{HL})$ \\
\hline călı́ dária & & & & & & \\
\hline LL $\underline{\sigma}$ & & & & & $* ! *$ & \\
\hline$(\mathbf{L L}) \underline{\sigma}$ & & & & & & \\
\hline
\end{tabular}

It should be observed that even if syncope did apply preferentially to HL sequences this can be understood in the present account: syncope in HL leads to avoiding a violation of $*(\mathrm{HL})$.

Finally, there was never deletion of a final vowel. We can account for this if we assume that the constraint FTBIN is dominated by NONFINALITY. The fact that the final vowel was never subject to syncope now follows directly from the 
constraint hierarchy, as illustrated in (12) and (13), given that the final vowel does not form a foot with the preceding stressed syllable.

(12)

\begin{tabular}{|c|c|c|c|c|c|c|}
\hline$/ \mathrm{LH} /$ & NONF & FTBIN & W/R & QS & PARSE- $\sigma$ & $*(\mathrm{HL})$ \\
\hline á-mō & & & & & & \\
\hline$(\underline{\mathrm{L} H})$ & $* !$ & & & $*$ & & \\
\hline$(\underline{\mathrm{L}}) \mathrm{H}$ & & $*$ & $\sigma$ & $*$ & $*$ & \\
\hline $\mathrm{L}(\underline{\mathrm{H}})$ & $* !$ & & & & $*$ & \\
\hline \hline /LL/ & NONF & FTBIN & W/R & QS & PARSE- $\sigma$ & $*(\mathrm{HL})$ \\
\hline cá-să & & & & & & \\
\hline$(\underline{\mathrm{LL}})$ & $* !$ & & & & & \\
\hline$(\underline{\mathrm{L}}) \mathrm{L}$ & & $*$ & $\sigma$ & & $*$ & \\
\hline
\end{tabular}

In the next section, we will briefly discuss the problematic cases of syncope in words such as opitumus and balineum, where it seems, at first sight, from the classical Latin stress pattern point of view, that the vowel with main stress is syncopated.

\subsection{Syncope in words of the type ŏpĭtŭmus and băliněum}

In order to understand syncope in these words, one should take into consideration the fact that the stress pattern of Plautinian Latin represents an intermediate stage between Pre-classical and Classical Latin. Stress in Pre-classical Latin was invariably on the first syllable of the word. By the time of Plautus, stress distribution was identical to Classical Latin, but for one context: it was on the initial syllable in words of four syllables, where the first three syllables were light. In other words, Plautinian Latin had a pre-antepenultimate pattern. Lindsay (1894) states with respect to the change from Pre-classical to Classical Latin stress:

At what precise period this change, no doubt a gradual one, from this earlier system to the Paenultima Law of Cicero's time began and completed itself, it is difficult to ascertain. But there is some evidence that it was still incomplete in one particular period of the Early Drama, for the metrical treatment of words like făcŭlius, mülǐerem in the plays of Plautus and Terence, indicate that the pronunciation of such words in their time laid the accent on the first, and not on the second syllable. [...] At the same time the incidence of the metrical ictus in all other types of words points to the prevalence of the Paenultima Law for all words, except for these quadrisyllables with the first three syllables short.

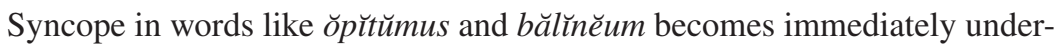
standable. Main stress in Plautinian Latin in tetrasyllabic words, with the first three syllables light, was on the first syllable, and not on the third from the 
end (cf. also Fraenkel 1928, Thierfelder 1928, and Allen 1973; 188) ${ }^{4}$. Syncope in these cases can be dated as having occurred between Pre-classical and Classical Latin. In Plautus, we find balineum only in unsyncopated form (cf. Burger 1928), later, in the classical period, as in Cicero's letters to Atticus, we sometimes find balneum and sometimes balineum ${ }^{5}$. In the Corpus Inscriptionum Latinarum we find optumи (CIL, i; 9) a tomb inscription from about 200 BC and opituma (CIL, i; 1206) also a tomb inscription dated later (end Republic/early Empire) by Lindsay (1894: 174). The later orthography optimus instead of optumus is due to Caesar (Quintilian, i. 7. 21).

Pre-classical Latin stress can be described by ranking the alignment constraints $\mathrm{W} / \mathrm{L}$ and $\mathrm{H} / \mathrm{L}$ above $\mathrm{W} / \mathrm{R}$ and $\mathrm{H} / \mathrm{R}$, which takes care of producing initial stress in every word. The evolution from Pre-classical to Plautinian/Early Latin can be described by inverting H/L and H/R as in (14) and (15) (cf. Jacobs (2003) for a more detailed account), where main stress is indicated by underscore and secondary stress by boldface. As a result, main stress will only be on the initial syllable in words of 4 syllables with the first three light, like fácilius 'easy adj.', fáciliter, 'easily adv.', básilicus 'royal', múlierem 'wife' and bálineum 'bath'.

\begin{tabular}{|l|c|c|c|c|c|c|}
\hline$/ \mathrm{LLLH} /$ & NONF & $\mathrm{W} / \mathrm{L}$ & $\mathrm{W} / \mathrm{R}$ & $\mathrm{H} / \mathrm{R}$ & $\mathrm{H} / \mathrm{L}$ & PARSE- $\sigma$ \\
\hline o-pi-tu-mus & & & & & & \\
\hline$(\underline{\mathrm{L}} \mathrm{L}) \mathrm{L}(\mathbf{H})$ & $* !$ & & & $\sigma \sigma$ & & $*$ \\
\hline $\mathrm{L}(\underline{\mathrm{L}} \mathrm{L}) \mathrm{H}$ & & $\sigma !$ & $\sigma$ & $\sigma$ & $\sigma$ & $* *$ \\
\hline$(\underline{\mathrm{L}} \mathrm{L})(\mathbf{L} \mathrm{H})$ & $* !$ & & & $\sigma \sigma$ & & \\
\hline$(\underline{\mathrm{L}} \mathrm{L}) \mathrm{L} \mathrm{H}$ & & & $\sigma \sigma$ & $\sigma \sigma$ & & $* *$ \\
\hline
\end{tabular}

The first two syllables of tetrasyllabic words with the first 3 syllables light again form a foot. And, again, syncope in such words as ŏp̆tumus and bălı̆neum can be understood as the deletion of a vowel in the weak position of a foot.

Words of more than 4 syllables or of 4 syllables, but with the first one heavy, are stressed in accordance with the Classical Latin stress pattern. In, for example, artículum 'joint', compósitus 'compounded', malefícium 'crime' or domicílium 'house' (cf, Allen (1973, Fraenkel (1928), Thierfelder (1928) and Lindsay (1894)), stress is on the third syllable form the right-edge, as corroborated by syncope. In compositus the second vowel can be deleted (compostus)

4. There seems to be no special reason why these words ( 4 syllables, first 3 light) are an exception. Morphology does not seem to be at stake, compare lábor fácilior 'easier work; nom.sg.' with labórem faciliórem 'easier work; acc. sg.', básilicus 'royal; nom.sg.' with basilicórum 'id.; gen.pl.' or máleficus 'evil' with malefícium 'crime'.

5. Ad Atticum, xiii. 52 about Caesar: inde ambulavit in litore. post $h$ VIII in balneum. 'After that he walked on the beach and at 2 in bath' and in ii.3 to Atticus: balineum calfieri iubebo. 'I shall have the bath heathened'. 
and in words of 5 syllables with the first 4 light, the vowel in the fourth syllable from the right-edge can be deleted, as in, officina 'working place' for opúficina and calfácere for căléfácere. Tableau (15) shows this for words such as opúficina (15a) and compósitus (15b). As before, main stress is indicated by underscore and secondary stress by boldface.

\begin{tabular}{|l|c|c|c|c|c|c|}
\hline a. $/$ LLLL $\sigma /$ & NONF & W/L & W/R & H/R & H/L & PARSE- $\sigma$ \\
\hline o-pi-fi-ci-na & & & & & & \\
\hline$(\underline{L} L)(\mathbf{L} L) \sigma$ & & & $\sigma$ & $\sigma \sigma ! \sigma$ & & $*$ \\
\hline$(\mathbf{L} L)(\underline{L} L) \sigma$ & & & $\sigma$ & $\sigma$ & $\sigma \sigma$ & $*$ \\
\hline L $(\underline{L} L)(\mathbf{L} \sigma)$ & $* !$ & $\sigma$ & & $\sigma \sigma$ & $\sigma$ & $*$ \\
\hline$(\mathbf{L} L) \mathrm{L}(\underline{L} \sigma)$ & $* !$ & & & & $\sigma \sigma \sigma$ & $*$ \\
\hline
\end{tabular}

\begin{tabular}{|l|c|c|c|c|c|c|}
\hline b. $/ \mathrm{H}$ L L $\sigma /$ & NONF & W/L & W/R & H/R & H/L & PARSE- $\sigma$ \\
\hline com-po-si-tus & & & & & & \\
\hline H $(\underline{L}$ L) $\sigma$ & & $\sigma !$ & $\sigma$ & $\sigma$ & $\sigma$ & $* *$ \\
\hline$(\mathbf{H})(\underline{\mathrm{L}} \mathrm{L}) \sigma$ & & & $\sigma$ & $\sigma$ & $\sigma$ & $*$ \\
\hline$(\underline{\mathrm{H}} \mathrm{L}) \mathrm{L} \sigma$ & & & $\sigma \sigma !$ & $\sigma \sigma$ & & $* *$ \\
\hline$(\underline{\mathrm{H}} \mathrm{L})(\mathbf{L} \sigma)$ & $* !$ & & & $\sigma \sigma$ & & \\
\hline$(\underline{\mathrm{H}})(\mathbf{L L}) \sigma$ & & & $\sigma$ & $\sigma \sigma ! \sigma$ & & $*$ \\
\hline
\end{tabular}

It should be observed that the first two candidates in (15b) both have main stress on the correct syllable, but differ only in whether or not there is a secondary stress on the initial syllable. We will return to this point below, and show in (19) that the actual pattern for Classical Latin should be the one in which there is no initial stress in these cases.

The further re-ranking of the constraints $\mathrm{W} / \mathrm{L}$ and $\mathrm{W} / \mathrm{R}$ produces the stress system of Classical Latin, where stress on the pre-antepenultimate syllable is no longer possible, as shown in (16).

\begin{tabular}{|c|c|c|c|c|c|c|c|}
\hline & /LLLH/ & NONF & $\mathrm{W} / \mathrm{R}$ & W/L & $H / R$ & $\mathrm{H} / \mathrm{L}$ & PARSE- $\sigma$ \\
\hline \multicolumn{8}{|c|}{ ba-li-ne-um } \\
\hline & $(\underline{L} \mathrm{~L}) \mathrm{L}(\mathbf{H})$ & *! & & & $\sigma \sigma$ & & * \\
\hline & $(\underline{L} \mathbf{L})(\mathbf{L ~ H})$ & *! & & & $\sigma \sigma$ & & \\
\hline 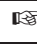 & $\mathrm{L}(\underline{\mathrm{L}} \mathrm{L}) \mathrm{H}$ & & $\sigma$ & $\sigma$ & $\sigma$ & $\sigma$ & $* *$ \\
\hline & $(\underline{L} \mathrm{~L}) \mathrm{LH}$ & & $\sigma \sigma !$ & & $\sigma \sigma$ & & $* *$ \\
\hline
\end{tabular}

Before providing an argument why an OT-account might be preferred over a rule-based account, let us first point out some further crucial rankings for Early Latin and Classical Latin.

The constraint hierarchy assumed thus far wrongly predicts initial stress in LH $\sigma$ words, as illustrated in (17) for fenéstram 'window'. 


\begin{tabular}{|l|c|c|c|c|c|c|c|}
\hline$/ \mathrm{LH \sigma} /$ & NONF & $\mathrm{W} / \mathrm{R}$ & $\mathrm{W} / \mathrm{L}$ & $\mathrm{Q} S$ & $\mathrm{H} / \mathrm{R}$ & $\mathrm{H} / \mathrm{L}$ & Parse- $\sigma$ \\
\hline fe-nes-tram & & & & & & & \\
\hline \multirow{2}{*}{$\underline{\mathrm{L}} \mathrm{H}) \mathrm{H}$} & & $\sigma$ & & $* *$ & $\sigma$ & & $*$ \\
\hline$\odot \mathrm{L}(\underline{\mathrm{H}}) \mathrm{H}$ & & $\sigma$ & $\sigma !$ & $*$ & $\sigma$ & $\sigma$ & $* *$ \\
\hline
\end{tabular}

To get main stress on the pre-final heavy syllable in fenestram 'window' and amīcum 'friend', the constraints QS must crucially dominate W/L as shown in (18).

\begin{tabular}{|l|c|c|c|c|c|c|c|}
\hline$/ \mathrm{LHH} /$ & NONF & W/R & QS & W/L & H/R & H/L & Parse- $\sigma$ \\
\hline fe-nes-tram & & & & & & & \\
\hline$(\underline{\mathrm{L}} \mathrm{H}) \mathrm{H}$ & & $\sigma$ & $* * !$ & & $\sigma$ & & $*$ \\
\hline $\mathrm{L}(\underline{\mathrm{H}}) \mathrm{H}$ & & $\sigma$ & $*$ & $\sigma$ & $\sigma$ & $\sigma$ & $* *$ \\
\hline
\end{tabular}

We also need to prevent secondary stress on the second syllable in initial LHsequences followed by main stress (19b-ii) and we need to prevent initial secondary stress if the first syllable is immediately followed by the syllable with main stress (19a-ii). This can be achieved by the ranking in (19), that is, by ranking CLASH above QS (the reader is again referred to Lahiri, Riad and Jacobs (1999) and Jacobs (2003) for a more detailed account of shortening). Given that we focus on the pre-main stress part of the words, the output candidates in (19) are evaluated only for that part, that is, the starting from main stress onwards, syllables are left out of consideration.

\begin{tabular}{|c|c|c|c|c|c|c|}
\hline \multicolumn{3}{|c|}{$/ \mathrm{H} \underline{\sigma} /$} & \multirow[t]{2}{*}{ CLASH } & \multirow[t]{2}{*}{$\mathrm{QS}$} & \multirow[t]{2}{*}{$\mathrm{W} / \mathrm{L}$} & PARSE- $\sigma$ \\
\hline & \multicolumn{2}{|c|}{ com-pó-si-tus } & & & & \\
\hline & \multirow{2}{*}{$\begin{array}{ll}\text { (i) } \\
\end{array}$} & $\mathrm{H} \underline{\sigma}$ & & * & $\sigma$ & * \\
\hline & & (H) $\underline{\sigma}$ & $* !$ & & & \\
\hline $\mathrm{b}$ & \multicolumn{2}{|c|}{ /LH西/ } & CLASH & QS & $\bar{W} / \mathrm{L}$ & PARSE- $\sigma$ \\
\hline & \multicolumn{2}{|c|}{ vò-lup-tátem } & & & & \\
\hline & \multirow{2}{*}{$\begin{array}{ll}(\mathrm{i}) & \text { (i) } \\
& \text { (ii }\end{array}$} & $(\mathbf{L ~ H}) \underline{\sigma}$ & & * & & \\
\hline & & $\mathrm{L}(\mathbf{H}) \underline{\bar{\sigma}}$ & $* !$ & & $\sigma$ & * \\
\hline c. & \multicolumn{2}{|l|}{ /LHL $\underline{\sigma} /$} & $\overline{\mathrm{CLASH}}$ & $\mathrm{QS}$ & $\overline{\mathrm{W} / \mathrm{L}}$ & PARSE- $\sigma$ \\
\hline & \multicolumn{2}{|c|}{ do-mès-ti-cátim } & & & & \\
\hline & \multirow[t]{2}{*}{ 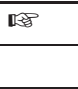 } & $\mathrm{L}(\mathbf{H}) \mathrm{L} \underline{\sigma}$ & & & $\sigma$ & $* *$ \\
\hline & & $(\mathbf{L ~ H}) \mathrm{L} \underline{\bar{\sigma}}$ & & $* !$ & & * \\
\hline
\end{tabular}

As illustrated in (19c), secondary stress is on the second syllable in initial LHsequences, only when the second heavy syllable is not followed immediately by main stress. It should be noticed that our OT-analysis of stress presented thus far follows with respect to the distribution of main and secondary stress exactly Allen (1973: 191), who, with respect to secondary stress, states that 
[w]ith very few exceptions (e.g., words with a pre-main stress LHL sequence [words such as siticulósus 'thirsty' or domesticátim 'in private houses' HJ] such a secondary stress will fall on the beginning of the word, i.e., the position of the prehistoric accent.

In this section, we have provided an OT-account of Latin stress, which has the benefit of uniformly identifying the context of syncope. All cases of syncope, throughout the history of Latin, can be regarded as targeting the same structural context: the weak position of the foot. Before turning to an analysis of the syncope process itself in the next section, we will first briefly address the question why an OT-account of Latin stress might be preferred over a more traditional rule-based account.

\section{Why Latin syncope might favor an OT-account}

In order to fully appreciate the differences between an OT-account of Latin stress and a rule-based account of Latin stress, it is instructive to look more closely at the contrast in prosodic structure between words, such as, ārĭdēre

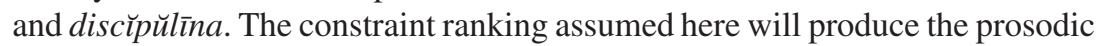
analysis given in (20) and (21).

\begin{tabular}{|l|c|c|c|c|c|c|c|c|}
\hline /HLHL/ & NONF & W/R & QS & W/L & H/R & H/L & PARSE- $\sigma$ & $*(\mathrm{HL})$ \\
\hline a-ri-dé-re & & & & & & & & \\
\hline$(\mathbf{H})$ L $(\underline{H})$ L & & $\sigma$ & & & $\sigma$ & $\sigma \sigma$ & $* * !$ & \\
\hline H L $(\underline{\mathrm{H}})$ L & & $\sigma$ & $* !$ & $\sigma \sigma$ & $\sigma$ & $\sigma \sigma$ & $* * *$ & \\
\hline (H L) $(\underline{\mathrm{H}}) \mathrm{L}$ & & $\sigma$ & & & $\sigma$ & $\sigma \sigma$ & $*$ & $*$ \\
\hline
\end{tabular}

\begin{tabular}{|c|c|c|c|c|c|c|c|c|}
\hline /HLLHL/ & NONF & $\mathrm{W} / \mathrm{R}$ & QS & $\mathrm{W} / \mathrm{L}$ & $\mathrm{H} / \mathrm{R}$ & $\mathrm{H} / \mathrm{L}$ & PARSE- $\sigma$ & $*(\mathrm{HL})$ \\
\hline dis-ci-pu-lí-na & & & & & & & & \\
\hline$(\mathbf{H} \mathrm{L}) \mathrm{L}(\underline{\mathrm{H}}) \mathrm{L}$ & & $\sigma$ & & & $\sigma$ & $\sigma \sigma \sigma$ & $* * !$ & $*$ \\
\hline $\mathrm{H}(\mathbf{L} \mathrm{L})(\underline{\mathrm{H}}) \mathrm{L}$ & & $\sigma$ & $* !$ & $\sigma$ & $\sigma$ & $\sigma \sigma \sigma$ & $* *$ & \\
\hline W $(\mathbf{H})(\mathbf{L ~ L})(\underline{\mathrm{H}}) \mathrm{L}$ & & $\sigma$ & & & $\sigma$ & $\sigma \sigma \sigma$ & * & \\
\hline
\end{tabular}

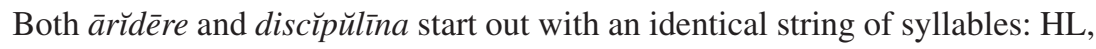
yet, for the application of syncope we want them to be parsed differently: in $\bar{a}$ rĭdēre the first two syllables ārĭ are grouped into a single foot, whereas the

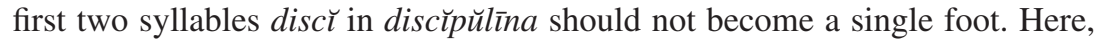
dis is a foot and $c \breve{p} \breve{u}$ a second foot. Syncope applies again to the vowel in the weak position of the foot: ārüdēre (ardere) and discŭpŭlīna (disciplina). A derivational analysis seems unable to produce this contrast. Either the identical initial sequence HL is grouped into a foot by using an uneven trochee or only the $\mathrm{H}$ syllable is analysed as a foot by using a moraic trochee. In a derivational approach, right-to-left stressing after main stress assignment (using an uneven 
trochee, that is allowing for a (HL) foot) seems to be the only way to produce the same contrasts. However, as shown by (22), derivationally speaking, stressing has to be from left-to-right, in order to prevent incorrectly secondary stress on the second syllable in words, such as, *similitúdinem 'similarity'. ${ }^{6}$

\begin{tabular}{|c|c|c|c|c|c|c|c|}
\hline /LLLHLH/ & NONF & W/R & W/L & H/R & H/L & PARSE- & $*(\mathrm{HL})$ \\
\hline sì-mi-li-tú-di-nem & & & & & & & \\
\hline L $(\mathbf{L}$ L $)(\underline{H}$ L $)$ H & & $\sigma$ & & $\sigma$ & $\sigma \sigma \sigma$ & $* *$ & $*$ \\
\hline
\end{tabular}

We have up until now argued that an OT-account is to be preferred over a derivational account because it allows us to provide a uniform identification of the context for vowel deletion in a more straightforward way. In the next section, we turn to the proper formulation of the deletion process itself.

\section{An OT foot-based analysis of categorical Latin vowel deletion?}

As mentioned above, Kager (1997) distinguishes two types of rhythmic vowel deletion: gradient and categorical. Gradient rhythmic vowel deletion preserves the syllabicity of the deleted vowel and preserves the foot-based context in the output. Categorical rhythmic vowel deletion is phonologically complete and destroys the syllabicity of the deleted vowel. For categorical vowel deletion there is no surface/output rhythmic pattern present by which deletion can be conditioned, and as Kager argues, categorical vowel deletion cannot be due to iterative feet, since that would involve opacity, but is due to the minimization of the number of unparsed syllables, which makes the analysis fully surfacebased and thus removes the opacity problem. For Latin, it is clear by now that, although syncope was governed by phonotactic considerations, it did nevertheless not lead to the minimization of the number of unparsed syllables and was thus not triggered by exhaustive parsing. In (23) a number of syncope cases in Latin are repeated.

a. valide $>$ valde

'very', 'strongly'

aliter > alter 'the one', 'the other'

propiter > propter 'because of', 'nearby'

solidus $>$ soldus 'solid'

olefacere $>$ olfacere 'to smell'

b. lamina > lamna 'metal plate'

barica > barca 'barque'

jugera $>$ jugra 'field'

6. Unless of course additional machinery is invoked such as destressing rules. 
The forms in (23a) all involve syncope of the second light syllable in initial LL sequences. Those in (23b) all involve syncope of the second light syllable after a preceding heavy syllable, that is, in initial HL sequences. Whereas the forms in (23b) might be interpreted as achieving exhaustive parsing, (under the assumption that HL does not form a foot), cases of syncope in initial LL sequences (23a), such as cálidus $>$ cáldus 'hot' or calefácere $>$ calfácere 'to heat' clearly show that exhaustive parsing cannot be the motivating force behind vowel deletion. The two light syllables before and the remaining heavy syllable after deletion are both perfect feet. In other words, Latin syncope does not abide by the typology set up by Kager (1997). It should be regarded as categorical and not as gradient. However, contrary to prediction it is not triggered by the desire of exhaustive metrical parsing. This brings back not only the opacity problem, but also the question as to how to formalize the syncope process.

Let us start by supposing that reduction/deletion is due to two factors: avoiding (HL) feet and (LL) feet, that is striving towards perfect bimoraic trochees. This can be expressed either directly by a constraint like *V IN (X.) (No vowel in the weak position of a foot (cf. Jacobs (2000)) or as the combined effect of the two constraints SWP (stressed syllable must be heavy) and *(HL) no uneven trochees. The standard ranking for Classical Latin assumed thus far is the one given in (24).

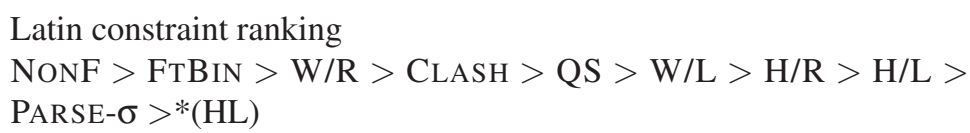

The constraints necessary for the application of syncope are given in (25):

$$
\begin{array}{ll}
* \mathrm{~V} \text { IN }(\mathrm{X} .) \quad(\text { No vowel in the weak position of the foot })<\text { SWP } \\
\mathrm{MAX}-\mathrm{V}-\mathrm{I} / \mathrm{O} \quad \text { (No vowel deletion })
\end{array}
$$

Given that distinctive vowel length is not affected by any of the processes (cf. līber 'free' lǐber 'book', lēgo 'I delegate' and lěgo 'I read'), (after all, vowel lengthening might be used to comply with SWP) the constraint against lengthening (DEP- $\sigma-\mathrm{IO})$ must be high-ranked.

Similarly, phonotactic constraints (here simply as PHON) must dominate the syncope constraint in order to express that syncope was governed by phonotactic well-formedness. Let us next suppose the optional rankings in (26a) and (26b). 


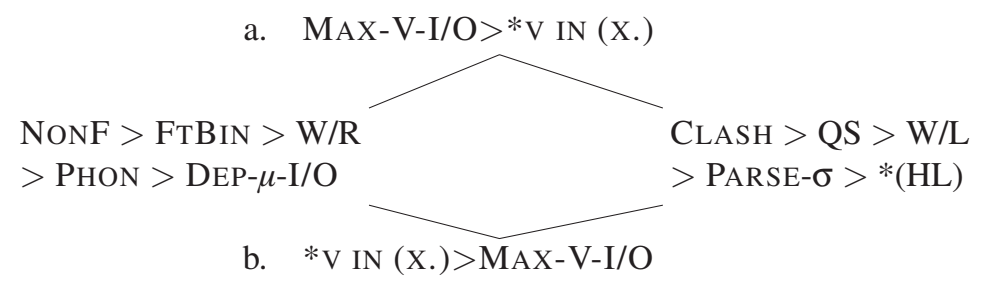

Ranking (26b) can be assumed to be the ranking responsible for syncope, as illustrated in the Tableaux (27)-(29). In these Tableaux, we have used \langle\rangle to embrace a syncopated vowel.

Tableau (27) illustrates the application of syncope in words such as, for example, lamina /HLL/, which becomes lamna $(\mathrm{H})\langle\mathrm{L}\rangle \mathrm{L}$.

\begin{tabular}{|c|c|c|c|c|c|c|c|c|}
\hline$/ \mathrm{HLL} /$ & NONF & W/R & $\begin{array}{c}* \mathrm{~V} \\
\text { IN (X.) }\end{array}$ & MAX-V & QS & W/L & PARSE- & $*(\mathrm{HL})$ \\
\hline lamina & & & & & & & & \\
\hline$(\underline{\mathrm{H}})(\mathrm{LL})$ & $* !$ & & & & & & & \\
\hline$(\underline{\mathrm{H}}) \mathrm{LL}$ & & $\sigma \sigma !$ & & & & & $* *$ & \\
\hline$\underline{\mathrm{H}})(\mathrm{L}) \mathrm{L}$ & & $\sigma$ & & $*$ & & & $*$ & \\
\hline$(\underline{\mathrm{H}}) \mathrm{L}$ & & $\sigma$ & $* !$ & & & & $*$ & $*$ \\
\hline$(\mathrm{H})(\underline{\mathrm{LL}})$ & $* !$ & & & & & & & \\
\hline
\end{tabular}

Tableau (28) shows the application of syncope in words of the type solidus $/ \mathrm{LHH} /$ becoming soldus $(\mathrm{L}+)\langle\mathrm{L}\rangle \mathrm{H}$. The notation $(\mathrm{L}+)$ indicates that the first syllable (so) becomes heavy ( $(\mathrm{sol})$ after syncope.

\begin{tabular}{|l|c|c|c|c|c|c|c|c|}
\hline$/ \mathrm{LLH} /$ & NONF & FTBIN & W/R & $* \mathrm{~V}$ & MAX-V & QS & PARSE- $\sigma$ & $*(\mathrm{HL})$ \\
\hline solidus & & & & & & & & \\
\hline$(\mathrm{LL})(\underline{\mathrm{H}})$ & $* !$ & & & $*$ & & & & \\
\hline$(\underline{\mathrm{LL}})(\mathrm{H})$ & $* !$ & & & $*$ & & & & \\
\hline$(\underline{\mathrm{L}})(\mathrm{L}) \mathrm{H}$ & & $\mathrm{L}+$ & $\sigma$ & & $*$ & $*$ & $*$ & \\
\hline$(\underline{\mathrm{LL}}) \mathrm{H}$ & & & $\sigma$ & $* !$ & & $*$ & $*$ & \\
\hline$(\mathrm{L})(\underline{\mathrm{LH}})$ & $* !$ & $*$ & & & & $*$ & & \\
\hline
\end{tabular}

In Tableau (29), we have illustrated syncope in words of the type aridus /HLH/ becoming ardus $(\mathrm{H})<\mathrm{L}>\mathrm{H}$. 
(29)

\begin{tabular}{|c|c|c|c|c|c|c|c|c|}
\hline /HLH/ & NONF & W/R & $\begin{array}{c}* V \\
\text { IN (X.) }\end{array}$ & MAX-V & QS & W/L & PARSE- & $*(\mathrm{HL})$ \\
\hline aridus & & & & & & & & \\
\hline$(\underline{\mathrm{H}}) \mathrm{L}(\mathrm{H})$ & $* !$ & & & & & & & \\
\hline$(\underline{\mathrm{H}}) \mathrm{LH}$ & & $\sigma \sigma !$ & & & $*$ & & $* *$ & \\
\hline$\underline{\underline{\mathrm{H}}})(\mathrm{L}\rangle \mathrm{H}$ & & $\sigma$ & & $*$ & $*$ & & $* *$ & \\
\hline$(\underline{\mathrm{H}}) \mathrm{H}$ & & $\sigma$ & $* !$ & & $*$ & & $*$ & $*$ \\
\hline$(\mathrm{H})(\underline{\mathrm{L}} \mathrm{H})$ & $* !$ & & & & $*$ & & & \\
\hline
\end{tabular}

It should be observed that the same ranking (26-b) accounts for pre-tonic syncope in word-initial LL-sequences, as illustrated in (30). An example is calfacere for călěfácere 'to heath'.

\begin{tabular}{|l|c|c|c|c|c|c|c|}
\hline$/ \mathrm{LL} \underline{\sigma} /$ & FTBIN & $* \mathrm{~V}$ & $\mathrm{MAX}-\mathrm{V}$ & $\mathrm{CLASH}$ & $\mathrm{W} / \mathrm{L}$ & PARSE- $\sigma$ & $*(\mathrm{HL})$ \\
\hline călĕfácere & & & & & & & \\
\hline$(\mathbf{L}) \mathrm{L} \underline{\sigma}$ & $* !$ & & & & & $*$ & \\
\hline$(\mathbf{L L}) \underline{\sigma}$ & & $* !$ & & & & & \\
\hline$(\mathbf{L}+)<\mathrm{L}>\underline{\sigma}$ & & & $*$ & $* !$ & & & \\
\hline \multirow{2}{*}{$\mathrm{L}+<\mathrm{L}>\underline{\sigma}$} & & & $*$ & & $\sigma$ & $*$ & \\
\hline
\end{tabular}

Please notice that is not always the case that the first syllable ends up as heavy, that is, becomes $\mathrm{L}_{+}$, as in calfacere. In cases such as veteránus > vetránus and figulina $>$ figlina, the remaining initial syllable stays light. This means that syncope cannot be due to the constraint SWP. Furthermore, it is clear from tableau (30), that, whether the remaining syllable of an LL sequence becomes heavy or not, this does not affect the outcome for pre-tonic syncope. It does, though, affect the outcome for syncope of a light syllable after a light main stressed syllable as in, for instance, the solidus cases like (28). The prediction is that syncope should not apply if the light stressed syllable remains light after syncope. This is illustrated in (31).

\begin{tabular}{|c|c|c|c|c|c|c|c|c|}
\hline /LLH/ & NONF & FTBIN & W/R & $\begin{array}{c}* \mathrm{~V} \\
\text { IN (X.) }\end{array}$ & MAX-V & QS & PARSE- $\sigma$ & $*(\mathrm{HL})$ \\
\hline leporem & & & & & & & & \\
\hline$(\mathrm{LL})(\underline{\mathrm{H}})$ & $* !$ & & & * & & & & \\
\hline$(\underline{\mathrm{LL}})(\mathbf{H})$ & *! & & & * & & & & \\
\hline$(\underline{\mathrm{L}})\langle\mathrm{L}\rangle \mathrm{H}$ & & $* !$ & $\sigma$ & & $*$ & $*$ & $*$ & \\
\hline 䟚 $(\underline{\mathrm{LL}}) \mathrm{H}$ & & & $\sigma$ & * & & * & * & \\
\hline$(\mathrm{L})(\underline{\mathrm{LH}})$ & $* !$ & $*$ & & & & & & \\
\hline
\end{tabular}

To the best of our knowledge, no such examples of syncope in Classical or Early Latin exist. In Late Latin and Early Gallo-Romance, cases of syncope in 
words of the prosodic shape of leporem are quite common. French lièvre 'hare' shows that the vowel remained short, if not, it would have turned into oi, as did long $e$ in regem $>$ roi 'king'. That the syllable did not become closed by geminating the consonant is shown by the fact that $p$ by lenition turned into $v$. Had it been long, it would like geminated $p$ have remained $p$, as in populum $>$ peuple 'people'. We will return to this point below.

Although for Classical Latin, the optional ranking assumed in (26b) can be shown to account for syncope in all cases, it fails in one context: it cannot account for HL sequences before main stress (the prototypical syncope cases according to Mester (1992)). Tableau (32) shows why it does not work for syncope in pre-tonic HL sequences, like ardère 'to burn' for *ārŭdēre, and ardōrem 'fire' for * ārŭdorem (cf. aridus).

\begin{tabular}{|c|c|c|c|c|c|c|}
\hline$/ \mathrm{HL} \underline{\sigma} /$ & *V IN (X.) & MAX-V & CLASH & $\mathrm{W} / \mathrm{L}$ & PARSE- $\sigma$ & $*(\mathrm{HL})$ \\
\hline ārĭdorem & & & & & & \\
\hline a. $(\mathbf{H}) \mathrm{L} \underline{\sigma}$ & & & & & * & \\
\hline b. $\quad(\mathbf{H L}) \underline{\sigma}$ & $* !$ & & & & & $*$ \\
\hline c. $\odot(\mathbf{H})\langle\mathrm{L}\rangle \underline{\sigma}$ & & $* !$ & * & & & \\
\hline d. $\odot \mathrm{H}\langle\mathrm{L}\rangle \underline{\sigma}$ & & $* !$ & & $\sigma$ & * & \\
\hline
\end{tabular}

Candidate (32a), the winning output in (32), has only one violation. It only violates PARSE- $\sigma$, a violation shared with candidate $(32 \mathrm{~d})$, which has more additional violations. In order to get $(32 \mathrm{c})$ as the actual output, we need to rank PARSE- $\sigma$ above the other constraints, as in (33), where candidate $\mathrm{c}$ now surfaces as optimal.

\begin{tabular}{|ll|c|c|c|c|c|c|}
\hline & /HL $\underline{\sigma} /$ & PARSE- $\sigma$ & $*$ V IN (X.) & MAX-V & CLASH & W/L & $*(\mathrm{HL})$ \\
\hline & ărĭdorem & & & & & & \\
\hline a. & $(\mathbf{H}) \mathrm{L} \underline{\sigma}$ & $* !$ & & & & & \\
\hline b. $\quad(\mathbf{H L}) \underline{\sigma}$ & & $* !$ & & & & $*$ \\
\hline c. $\quad(\mathbf{H})\langle\mathrm{L}\rangle \underline{\sigma}$ & & & $*$ & $*$ & & \\
\hline d. $\quad \mathrm{H}\langle\mathrm{L}\rangle \underline{\sigma}$ & $* !$ & & $*$ & & $\sigma$ & \\
\hline
\end{tabular}

However, as shown above in (18), to get main stress on the pre-final heavy syllable in words like fenéstram 'window' and amícum 'friend', the constraints QS must dominate W/L and PARSE- $\sigma$. The constraint CLASH, as illustrated in (19), crucially dominates the constraint QS. If PARSE- $\sigma$ dominates CLASH (which it must crucially in (33) in order not to rule out the winning candidate) it must, by transitivity, also dominate QS and W/L, thereby wrongly producing initial stress in LHo-words, as illustrated in (34). 


\begin{tabular}{|c|c|c|c|c|c|c|c|}
\hline \multicolumn{2}{|c|}{$\begin{array}{l}/ \mathrm{LH} \sigma / \\
\text { fe-nes-tram }\end{array}$} & NONFIN & $\bar{W} / \mathrm{R}$ & PARSE- $\sigma$ & CLASH & QS & $\mathrm{W} / \mathrm{L}$ \\
\hline \multicolumn{8}{|c|}{ fe-nes-tram } \\
\hline 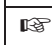 & $(\underline{\mathrm{L}} \mathrm{H}) \mathrm{L}$ & & $\sigma$ & $\sigma$ & & * & \\
\hline & $\mathrm{L}(\underline{\mathrm{H}}) \mathrm{L} \odot$ & & $\sigma$ & $\sigma \sigma !$ & & & $\sigma$ \\
\hline
\end{tabular}

The temporary conclusion therefore seems to be that it is impossible to have one and the same ranking deal with both stress distribution and with the syncope facts. In order to drive this point fully home, let us first try to derive the wanted candidate in pre-tonic HL sequences (cf. Tableaux (32) and (33)) by changing the constraint responsible for syncope. If, instead of making it refer to the structural position foot, it is reformulated as simply referring to poststress position, the problematic candidate (32a) will be ruled out given that the stressed vowel is still followed by an unstressed vowel, albeit not in the same foot. This is illustrated in (35).

\begin{tabular}{|ll|c|c|c|c|c|c|}
\hline & /HL $\underline{\sigma} /$ & $* V$ IN X. & MAX-V & CLASH & W/L & PARSE- $\sigma$ & $*(\mathrm{HL})$ \\
\hline & ărĭdorem & & & & & & \\
\hline a. & $(\mathbf{H}) \mathrm{L} \underline{\sigma}$ & $* !$ & & & & $*$ & \\
\hline b. & $(\mathbf{H L}) \underline{\sigma}$ & $* !$ & & & & & $*$ \\
\hline c. & $(\mathbf{H})<\mathrm{L}>\underline{\sigma}$ & & $*$ & $* !$ & & & \\
\hline d. $\quad$ & $\mathrm{H}<\mathrm{L}>\underline{\sigma}$ & & $*$ & & $\sigma$ & $*$ & \\
\hline
\end{tabular}

This alternative, although it solves the pre-tonic HL cases, leads to more problems than it solves. Although it now works for syncope before main stress, it makes the wrong predictions for all syncope cases after main stress as in the cases (28) to (30). This is so, because after syncope of the penultimate vowel, there still will be a violation of the modified constraint: the stressed syllable will be followed by the final unstressed syllable. This is illustrated in (36) for one of these cases.

\begin{tabular}{|c|c|c|c|c|c|c|c|c|}
\hline /HLL/ & $\mathrm{NONF}$ & $\mathrm{W} / \mathrm{R}$ & \begin{tabular}{|c|}
$* \mathrm{~V}$ \\
IN $\mathrm{X}$
\end{tabular} & MAX-V & QS & $\mathrm{W} / \mathrm{L}$ & PARSE- $\sigma$ & $*(\mathrm{HL})$ \\
\hline lamina & & & & & & & & \\
\hline$(\underline{\mathrm{H}})(\mathrm{LL})$ & $* !$ & & * & & & & & \\
\hline$(\underline{\mathrm{H}}) \mathrm{LL}$ & & $\sigma \sigma !$ & * & & & & $* *$ & \\
\hline$(\underline{\mathrm{H}})\langle\mathrm{L}\rangle \mathrm{L} \odot$ & & $\sigma$ & * & $* !$ & & & * & \\
\hline 四 $(\underline{\mathrm{HL}}) \mathrm{L}$ & & $\sigma$ & * & & & & * & * \\
\hline \begin{tabular}{|l}
$(\mathrm{H})(\underline{\mathrm{LL}})$ \\
\end{tabular} & $* !$ & & * & & & & & \\
\hline
\end{tabular}

Furthermore, there is another case of syncope where an analysis using a constraint for syncope which only refers to post-stress position, but not foot-constituency, will fail: syncope in cases, such as manı̆pulus > maniplus 'fistful, bundle', aurı̌cula $>$ auricla 'ear' and solı̌culum $>$ soliclu 'sun' (cf. Bullock 
(2001) for an analysis of these cases in relation with Late Latin stress shift in notoriously difficult cases like integrum $>$ intégrum). The interesting point is that in these cases the antepenultimate vowel is short, hence making the syllable light, contrary to cases like periculum $>$ periclum, where the vowel is long. French péril (long $i$ remained as $i$ ) and soleil (short $i$ merged with long $e$ ) show that the vowels remained distinctive throughout the evolution from Latin to French. This means that after syncope a light stressed syllable remains. Let us first illustrate in (37) that the constraint ranking with the constraint for syncope modified in such a way as to refer to post-stress position only, is unable to handle syncope in these cases.

\begin{tabular}{|c|c|c|c|c|c|c|c|c|}
\hline /HLLH/ & NONF & FTBIN & $\begin{array}{c}* \mathrm{~V} \\
\text { IN } \mathrm{X} \\
\end{array}$ & MAX-V & Clash & $\mathrm{W} / \mathrm{L}$ & PARSE- $\sigma$ & $*(\mathrm{HL})$ \\
\hline so-li-cu-lum & & & & & & & & \\
\hline$(\mathbf{H})(\underline{\mathrm{LL}}) \mathrm{H}$ & & & $*$ & & $* !$ & & * & \\
\hline$(\mathbf{H})(\underline{L L})(\mathbf{H})$ & $* !$ & & * & & * & & & \\
\hline$(\mathbf{H})(\underline{L})\langle\mathrm{L}\rangle \mathrm{H}$ & & *! & * & * & * & & * & \\
\hline $\mathrm{H}(\underline{\mathrm{L}})\langle\mathrm{L}\rangle \mathrm{H} \odot$ & & $* !$ & * & * & & $\sigma$ & $* *$ & \\
\hline e. $\quad \mathrm{H}(\underline{\mathrm{L}}+)\langle\mathrm{L}\rangle \mathrm{H} \odot$ & & & $*$ & $* !$ & & $\sigma$ & $* *$ & \\
\hline f. $\quad(\underline{\mathrm{H}}) \mathrm{L}\langle\mathrm{L}\rangle \mathrm{H}$ & & & $*$ & $* !$ & & & $* *$ & \\
\hline g. $\quad(\underline{\mathrm{H}})\langle\mathrm{L}\rangle\langle\mathrm{L}\rangle \mathrm{H}$ & & & $*$ & $* ! *$ & & & * & \\
\hline h. $\mathrm{H}(\underline{\mathrm{L} L}) \mathrm{H}$ & & & * & & & $\sigma$ & $* *$ & \\
\hline 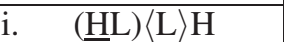 & & & $*$ & $* !$ & & & $*$ & $*$ \\
\hline
\end{tabular}

This Tableau clearly shows that there is simply no way to get the correct candidate, no matter what the ranking of the constraints is. The winning candidate (37h) has the same violations marks as both the losing candidates (37d) and (37e), which themselves, moreover, have more losing marks. Even if we were to assume that, given that vowel length is not affected, the syllable became heavy after syncope (expressed by candidate (37e) and referred to as 'doubtful quantity' by Bullock (2001)), vowel deletion will still not take place.

It is instructive to see what happens to soliculum cases with a foot-based syncope constraint: *V IN (X.), which we just abandoned for the sake of pretonic syncope in HL sequences. This is illustrated in (38). 
(38)

\begin{tabular}{|c|c|c|c|c|c|c|c|c|}
\hline /HLLH/ & FTBIN & W/R & *V IN (X.) & MAX-V & CLASH & $\mathrm{W} / \mathrm{L}$ & PARSE & $*(\mathrm{HL})$ \\
\hline so-li-cu-lum & & & & & & & & \\
\hline (H) $(\underline{\mathrm{LL}}) \mathrm{H}$ & & $\sigma$ & $* !$ & & * & & * & \\
\hline $\begin{array}{ll}\text { b. } & (\mathbf{H})(\underline{\mathrm{L}})\langle\mathrm{L}\rangle \mathrm{H}\end{array}$ & $* !$ & $\sigma$ & & $*$ & $*$ & & * & \\
\hline c. $\quad \mathrm{H}(\underline{\mathrm{L}})\langle\mathrm{L}\rangle \mathrm{H}$ & $* !$ & $\sigma$ & & * & & $\sigma$ & $* *$ & \\
\hline d. 1 眵 $\mathrm{H}(\underline{\mathrm{L}}+)\langle\mathrm{L}\rangle \mathrm{H}$ & $?$ & $\sigma$ & & $*$ & & $\sigma$ & $* *$ & \\
\hline 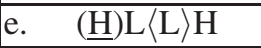 & & $\sigma \sigma !$ & & $*$ & & & $* *$ & \\
\hline f. ${ }^{\prime}(\underline{\mathrm{H}})\langle\mathrm{L}\rangle\langle\mathrm{L}\rangle \mathrm{H}$ & & $\sigma$ & & $* * !$ & & & * & \\
\hline $\begin{array}{ll}\text { g. } & \mathrm{H}(\underline{\mathrm{LL}}) \mathrm{H}\end{array}$ & & $\sigma$ & $* !$ & & & $\sigma$ & $* *$ & \\
\hline h. $\quad(\underline{\mathrm{HL}})\langle\mathrm{L}\rangle \mathrm{H}$ & & $\sigma$ & $* !$ & * & & & $*$ & * \\
\hline i. $\quad(\underline{\mathrm{LL}})\langle\mathrm{L}\rangle \mathrm{H}$ & & $\sigma$ & $* !$ & & & & & \\
\hline
\end{tabular}

Candidate (38d) is the winning candidate, but of course only, if it is assumed that the syllable effectively became heavy (closed given that the vowel remained short). Without this assumption, candidate (38f; * solclum) with a stress shift to the first syllable would be the winning one. Instead of assuming that the syllable became heavy after syncope, one might consider invoking an O-O stress identity constraint, requiring stress to stay on the same syllable in related forms. Neither solution is attractive. O-O stress identity is at odds with the normal stress behaviour of morphologically related forms in Latin (cf. négat 'he/she denies' rénegat 'he/she denies again'). Assuming that the syllable became closed is at odds with the later behaviour of words like leporem as discussed above. The Romance evidence is not entirely conclusive. French shows on the one hand that the vowel remained light (cf. the soleil $\sim$ péril contrast discussed above). On the other hand, it is clear that at some point the syllable did become a closed one, given that no diphthongization of $e$ (former short $i$ ) took place, the normal evolution of stressed $e$ in open syllables, and which would have resulted in French oi (as in niger > noir 'black' and regem > roi 'king'). The closure of the syllable is traditionally assumed to have taken place after the palatalisation of the velar to $j$ (the normal evolution of simplex velars by lenition). Compare factum $>$ fait 'fact' and pacare > paier 'to pay'. Similarly $p$ and $b$ in post-vocalic $b l$ and $p l$-cluster became geminated, but later in the history (cf. duplu (geminated after voicing (part of lenition)) Old French doble 'double'. Italian occhio 'eye' (< oculum) and vecchio 'old' (<vetulus) show gemination of post-vocalic velar+ $l$ clusters. Furthermore, and most importantly, even if we were to count the syllable as heavy providing it with a mora that is not realised, more to the spirit of Bullock's 'doubtful quantity', we still have no account for pre-tonic syncope in word-initial HL-sequences.

The inevitable conclusion therefore is that it seems simply impossible to handle all the syncope cases with one and the same constraint hierarchy. A foot-based account is necessary for syncope after main stress, but fails for syncope in HL sequences before main stress and cannot account for syncope in 
soliculum cases and later leporem cases without additional assumptions or machinery. An alternative account where the syncope constraint is reformulated without making reference to the foot only works for the pre-tonic HL syncope cases, but fails in all other cases.

This is precisely the heart of the opacity problem. It should be noticed that it is a different kind of opacity, though, than the cases discussed in Kager (1997). It is not the case, derivationally speaking, that, as in South-eastern Tepehuan, a layer of iterative feet is constructed to condition the application of syncope, a layer that is subsequently deleted, because at the surface there is no rhythmic pattern in the language. In the case of Latin, there is a surface rhythmic pattern, but the opacity arises due to the conflict between, still derivationally speaking, on the one hand stress assigning structure-building rules and on the other hand the syncope rule which is structure-dependent and structure-changing. Or, to put it more precisely, the actual output of syncope renders the prosodic generalizations of the language opaque. In the next section, we will consider a number of ways to account for this opacity aspect of Latin syncope.

\section{Syncope and opacity}

In the recent OT-literature a number of approaches to deal with opacity have been formulated (cf. Kager 1999: 372-400 for an overview). We will first compare the syncope opacity effects with the standard opacity cases discussed in the literature. Kager (1999) distinguishes opaque generalizations that are 'nonsurface-true' and those that are 'non-surface-apparent', which lead to respectively underapplication (cf. Isthmus Nahuat Approximant Devoicing) and overapplication (cf. Turkish Vowel Epenthesis). Latin Syncope is neither characterized by overapplication nor by underapplication, it has the effect that at the surface the otherwise prosodic well-formedness constraints do not hold for the forms to which syncope has applied, which is most clearly illustrated by the conflicting demands of tableaux (33) and (34). Kager (1999: 380) discusses a third type of opacity, where the opaque generalizations hold at an intermediate level of prosodic structure, Oromo Compensatory Lengthening, illustrated in (39).
a. /fed-na/ feena 'we wish'
b. /fed-sisa/ feesisa 'I make wish'
c. /fed-a/ feda 'I wish'
d. /fed-adda/ fedadda 'wish for self'

A coda consonant acquires a mora, which is preserved as length on the preceding vowel if the coda consonant is deleted before a consonant-initial suffix. The counter-bleeding order Weight-by-position followed by Pre-consonantal dele- 
tion explains the opacity. This kind of opacity is closer to Latin syncope, but different in that the actual output in Oromo obeys prosodic well-formedness, whereas the actual outputs for Latin do not.

Let us next look at some ways that have been proposed to handle opacity in OT. First, let us consider O-O faithfulness constraints. Given that we are dealing with rhythmical deletion, relying on Output-Output constraints seems to be excluded. Also, in a lot of cases there is simply no other output to which the output form with syncope can be said to be faithful. Compare:

$\begin{array}{lll}\text { Syncope } & \text { Related form } \\ \text { figulina } & >\text { figlina } & \text { figulus } \\ \text { discipulina } & >\text { disciplina } & \text { discipulus }\end{array}$

Another approach to opacity, Sympathy Theory (McCarthy 1997) does not seem to be helpful either. We will briefly illustrate how sympathy works by looking at Turkish. In Turkish, the interaction between Velar deletion (40a) and Vowel epenthesis (40b) produces the opaque forms in (40c).
a. Velar deletion
/ajak-I/ [ajai] 'his foot'
/inek-I/ [inei] 'his cow'
b. Vowel epenthesis
$\begin{array}{lll}\text { /baf-m/ } & {[\mathrm{ba} f \mathrm{im}]} & \text { 'my head' } \\ / \mathrm{jel}-\mathrm{m} / & {[\mathrm{jelim}]} & \text { 'my wind' }\end{array}$
c. Opacity
/ajak-m/ [ajaim] 'my foot'
linek-m/ [ineim] 'my cow'

Ranking the constraints *COMPLEX, MAX-IO, DEP-IO and the constraint responsible for Velar deletion $* \mathrm{VkV}$ as in (41) shows that the normal ranking will lead to the wrong result.

\begin{tabular}{|ll|c|c|c|c|}
\hline & /ajak-m/ & $*$ COMPLEX & $* V k V$ & MAX-IO & DEP-IO \\
\hline a. & a.jakm & $* !$ & & & \\
\hline b. & a.ja.kim & & $* !$ & & $*$ \\
\hline c. & a.jam & & & $*$ & \\
\hline d. & a.ja. im & & & $*$ & $* !$ \\
\hline
\end{tabular}

In order to get (41d) as the actual output, the opaque output is measured in terms of correspondence to another output candidate, the sympathy or sympathetic candidate. The 8 -candidate is [a.ja.kim]. The correspondence constraint demanding faithfulness to the sympathy candidate is the constraint MAX-\&O and is ranked above DEP-IO, as illustrated in (42) (cf. Kager 1999 for a more detailed account). 


\begin{tabular}{|ll|c|c|c|c|c|}
\hline & /ajak-m/ & $*$ COMPLEX & $* \mathrm{VkV}$ & MAX-\&O & MAX-IO & DEP-IO \\
\hline a. & a.jakm & $* !$ & & $*$ & & \\
\hline b. & a.ja.kim & & $* !$ & & & $*$ \\
\hline c. & a.jam & & & $* * !$ & $*$ & \\
\hline d. $\quad$ a.ja. im & & & $*$ & $*$ & $*$ \\
\hline
\end{tabular}

McCarthy restricts selectors for ${ }^{8}$-candidates to $\mathrm{I} / \mathrm{O}$ faithfulness constraints. That is, the opaque output comes out as winner by satisfying/resembling more closely the sympathy candidate than the actual winning candidate without sympathy constraints. Let us return to the problematic Latin case, repeated here as (43).

\begin{tabular}{|c|c|c|c|c|c|c|}
\hline /HL $\underline{\sigma} /$ & *V IN (X.) & MAX-V & CLASH & $\mathrm{W} / \mathrm{L}$ & PARSE- $\sigma$ & $*(\mathrm{HL})$ \\
\hline ārĭdorem & & & & & & \\
\hline a. $(\mathbf{H}) \mathrm{L} \underline{\sigma}$ & & & & & * & \\
\hline b. $\quad(\mathrm{HL}) \underline{\sigma}$ & $* !$ & & & & & * \\
\hline $\begin{array}{c}\text { c. } \odot(\mathbf{H})\langle\mathrm{L}\rangle \\
\underline{\sigma}\end{array}$ & & $* !$ & * & & & \\
\hline d. $\odot \mathrm{H}\langle L\rangle \underline{\sigma}$ & & $* !$ & & $\sigma$ & * & \\
\hline
\end{tabular}

Although the second candidate might function as the sympathy candidate, there seems to be no way in which we could make (43c) and not (43a) come out as winning candidate. This is so because the constraint PARSE- $\sigma$ is not an I/O faithfulness constraint.

How to account for syncope then? Another approach to opacity has been the assumption of a multi-level OT-phonology, where evaluation takes place in steps (cf., among others, Booij (1997), Rubach (1997) and Kiparsky (1998)). For Latin syncope, we assume that the standard (or lexical) constraint ranking is the one in (27a). The post-lexical ranking could then be identified as one in which PARSE- $\sigma$ dominates CLASH (necessary as shown in (34) above) and in which FTBIN is ranked below the syncope constraints (necessary as shown in (39) above). Furthermore, as in derivational theory, lexical stress has to be preserved post-lexically, if not, words of the shape LHo (fenestram) would obviously still come out wrong. To this effect we need a constraint IDENT-STRESS$\mathrm{O} / \mathrm{I}$ (I-S), a constraint, which requires that stress in the output corresponds to stress in the input. The input to the post-lexical level is then the prosodically organized output of the preceding level. In Tableaux (44) to (49) it is shown how this works for the examples discussed in this paper. 
(44)

\begin{tabular}{|c|c|c|c|c|c|c|c|c|c|}
\hline & $/ \mathrm{H}(\underline{\mathrm{LL}}) \mathrm{H} /$ & I-S & PARSE & $\begin{array}{c}* \mathrm{~V} \\
\text { IN (X.) } \\
\end{array}$ & MAX-V & FTBIN & Clash & $\mathrm{W} / \mathrm{L}$ & $*(\mathrm{HL})$ \\
\hline & so-li-cu-lum & & & & & & & & \\
\hline a. & $(\mathbf{H})(\underline{\mathrm{LL}}) \mathrm{H}$ & $* !$ & $*$ & $*$ & & & $*$ & & \\
\hline b. & $(\mathbf{H})(\underline{\mathrm{L}})\langle\mathrm{L}\rangle \mathrm{H}$ & $* !$ & $*$ & & $*$ & $*$ & $*$ & & \\
\hline c. $\log ^{\circ}$ & $\mathrm{H}(\underline{\mathrm{L}})\langle\mathrm{L}\rangle \mathrm{H}$ & & $* *$ & & $*$ & $*$ & & $\sigma$ & \\
\hline d. $\quad$ & $\mathrm{H}(\underline{\mathrm{L}}+)\langle\mathrm{L}\rangle \mathrm{H}$ & & $* *$ & & $*$ & $*$ & & $\sigma$ & \\
\hline e. & $(\underline{\mathrm{H}}) \mathrm{L}\langle\mathrm{L}\rangle \mathrm{H}$ & $* !$ & $* *$ & & $*$ & & & & \\
\hline f. & $(\underline{\mathrm{H}})\langle\mathrm{L}\rangle\langle\mathrm{L}\rangle \mathrm{H}$ & $* !$ & $*$ & & $* *$ & & & & \\
\hline g. & $\mathrm{H}(\underline{\mathrm{LL}}) \mathrm{H}$ & & $* *$ & $* !$ & & & & $\sigma$ & \\
\hline h. & $(\underline{\mathrm{HL}})\langle\mathrm{L}\rangle \mathrm{H}$ & $* !$ & $*$ & * & $*$ & & & & $*$ \\
\hline i. & $(\underline{\mathrm{LL}})\langle\mathrm{L}\rangle \mathrm{H}$ & $* !$ & * & * & * & & & & \\
\hline
\end{tabular}

Of the two optimal candidates $(44 \mathrm{c})$ and $(44 \mathrm{~d})$, candidate (44d) will be ruled out by the constraint DEP- $\mu$-I/O which is not included in (44). Wherever it is located, it will rule out (44d).

(45)

\begin{tabular}{|ll|l|c|c|c|c|c|c|c|}
\hline & $(\mathrm{HL}) \mathrm{L} /$ & $\mathrm{I}-\mathrm{S}$ & NONF & PARSE & $* \mathrm{~V}$ IN $(\mathrm{X})$. & MAX-V & FTB IN & CLASH & $*(\mathrm{HL})$ \\
\hline & lamina & & & & & & & & \\
\hline a. & $(\underline{\mathrm{H}})(\mathrm{LL})$ & $* !$ & $*$ & & & & & $*$ & \\
\hline b. $\quad(\underline{\mathrm{H}}) \mathrm{LL}$ & & & $* * !$ & & & & & \\
\hline c. $\quad(\underline{\mathrm{H}})(\mathrm{L}) \mathrm{L}$ & & & $*$ & & $*$ & & & \\
\hline d. & $(\underline{\mathrm{H}}) \mathrm{L}$ & & & $*$ & $* !$ & & & & $*$ \\
\hline e. & $(\underline{\mathrm{H}})(\mathrm{LL})$ & $* !$ & $*$ & $*$ & & & & $*$ & \\
\hline
\end{tabular}

(46)

\begin{tabular}{|c|c|c|c|c|c|c|c|c|c|}
\hline & /(LL)H/ & I-S & NONF & PARSE & *V IN (X.) & MAX-V & FTBIN & CLASH & $*(\mathrm{HL})$ \\
\hline & solidus & & & & & & & & \\
\hline a. & $(\underline{L L})(\mathbf{H})$ & $* !$ & * & & * & & & & \\
\hline b. & (LL)H & & & * & $* !$ & & & & \\
\hline c. & $(\underline{L})\langle\mathrm{L}\rangle \mathrm{H}$ & & & * & & * & $* !$ & & \\
\hline d. 踭 & $(\underline{\mathrm{L}}+)<\mathrm{L}>\mathrm{H}$ & & & * & & * & & & \\
\hline e. & $(\underline{\mathrm{L}})(\mathbf{L H})$ & $* !$ & * & & & & & * & \\
\hline
\end{tabular}

(47)

\begin{tabular}{|ll|l|c|c|c|c|c|c|c|}
\hline & $/(\mathrm{HL}) \mathrm{H} /$ & $\mathrm{I}-\mathrm{S}$ & NONF & PARSE & $* \mathrm{~V}$ IN $(\mathrm{X})$. & MAX-V & FTB BN & CLASH & $*(\mathrm{HL})$ \\
\hline & aridus & & & & & & & & \\
\hline a. & $(\underline{\mathrm{H}}) \mathrm{L}(\mathbf{H})$ & $* !$ & $*$ & & & & & & \\
\hline b. $\quad(\underline{\mathrm{H}}) \mathrm{LH}$ & & & $* * !$ & & & & & \\
\hline c. & $(\underline{\mathrm{H}})(\mathrm{L}\rangle \mathrm{H}$ & & & $*$ & & $*$ & & & \\
\hline d. & $(\underline{\mathrm{H}})(\mathbf{L H})$ & $* !$ & $*$ & & & & & $*$ & \\
\hline e. & $(\underline{\mathrm{H}} \mathrm{L}) \mathrm{H}$ & & & $*$ & $* !$ & & & & $*$ \\
\hline
\end{tabular}




\begin{tabular}{|ll|l|l|l|l|l|l|l|l|}
\hline & $/(\underline{\mathrm{HL}}) \underline{\underline{\sigma}} /$ & $\mathrm{I}-\mathrm{S}$ & NONF & PARSE & $* \mathrm{~V}$ IN $(\mathrm{X})$. & MAX-V & FTB IN & CLASH & $*(\mathrm{HL})$ \\
\hline & calefácere & & & & & & & & \\
\hline a. $\quad(\mathbf{L}) \mathrm{L} \underline{\underline{\sigma}}$ & & & $* !$ & & & $*$ & & \\
\hline b. $\quad(\mathbf{L L}) \underline{\sigma}$ & & & & $* !$ & & & & \\
\hline c. $\quad(\mathbf{L}+)\langle\mathrm{L}\rangle \underline{\sigma}$ & & & & & $*$ & & $*$ & \\
\hline d. $\quad \mathrm{L}+\langle\mathrm{L}\rangle \underline{\sigma}$ & & & $* !$ & & $*$ & & & \\
\hline
\end{tabular}

\begin{tabular}{|c|c|c|c|c|c|c|c|c|}
\hline$/(\underline{\mathrm{HL}}) \underline{\sigma} /$ & $\mathrm{I}-\mathrm{S}$ & NONF & PARSE & *V IN (X.) & MAX-V & FTBIN & CLASH & $*(\mathrm{HL})$ \\
\hline$\overline{\text { ärŭdorem }}$ & & & & & & & & \\
\hline $\mathrm{H}\langle\mathrm{L}\rangle \underline{\sigma}$ & & & $* !$ & & * & & & \\
\hline b. $(\mathbf{H})\langle\mathrm{L}\rangle \underline{\sigma}$ & & & & & * & & * & \\
\hline (HL) $\underline{\sigma}$ & & & & *! & & & & * \\
\hline d. $\quad(\mathbf{H}) \mathrm{L} \underline{\sigma}$ & & & $* !$ & & & & & \\
\hline
\end{tabular}

In this section, we have discussed briefly various approaches to the opacity problem. We have shown that a unified account of Latin syncope is possible only if constraint evaluation takes place in levels. The immediate advantage of the analysis, besides that it seems to be the only way of accounting for syncope, is that it straightforwardly captures the variability of syncope and is able to preserve the traditional view of sound change starting as optional change entering the post-lexical phonology.

There is, however, yet another way of accounting for syncope that we would like to briefly comment on and which avoids a multiple-level OT-phonology. A crucial aspect of the analysis, formalized by the constraint IDENT-STRESS-O/I (I-S), is that stress in the output corresponds to stress in the input. We might alternatively consider the ranking in (27a) as expressing generalizations over the lexicon, much in the same way as stress-assigning rules have sometimes (Hayes 1981) been considered lexical redundancy rules. On that view, we could assume stress or prosodic structure to be present in the input and vowel deletion to be the result of an optional ranking in which PARSE- $\sigma$ dominates CLASH (cf. (34)) and in which FTBIN is ranked below the syncope constraints (cf. (39)).

\section{Summary}

In this paper we have discussed syncope in Latin. In the first part of the paper we have shown how a slightly modified OT-account of Latin stress can identify the context for syncope in a uniform way: the weak position of a foot. After that, we have shown that syncope is categorical, but is not triggered by exhaustive parsing. The last part of the paper has shown that a foot-based OT analysis is possible only if constraint evaluation takes place in levels. The immediate advantage of the analysis, besides that it seems to be the only way of accounting for syncope, is that it straightforwardly captures the variability of syncope 
and is able to preserve the traditional view of sound change starting as optional change entering the post-lexical phonology.

University of Nijmegen

\section{References}

Allen, William Sidney (1973). Accent and Rhythm. Cambridge: Cambridge University Press. Booij, Geert (1997). Non-derivational phonology meets lexical phonology. In Derivations and Constraints in Phonology, Iggy Roca (eds.), 261-288. Oxford: Clarendon Press.

Bullock, Barbara (2001). Double Prosody and Stress Shift in Proto-Romance. Probus 13 (2): 173 192.

Burger, André (1928). Etudes de phonétique et de morphologie latines. Neuchatel, Recueil de travaux publiés par la Faculté des lettres, fascicule 13.

Corssen, Wilhelm (1870). Über Aussprache, Vokalismus und Betonung der lateinischen Sprache. Leipzig: Teubner.

Fraenkel, Eduard (1928). Iktus und Akzent im lateinischen Sprechvers. Berlin: Weidmannsche Buchhandlung.

Hayes, Bruce (1995). Metrical Stress Theory: Principles and Case Studies. Chicago: Chicago University Press.

Jacobs, Haike (1989). Nonlinear studies in the historical phonology of French. Diss. Nijmegen.

- (1999). Constraining constraints: NonFinality and the typology of foot-extrametricality. In Linguistics in the Netherlands 1999, René Kager and René van Bezooijen (eds.), 111-120. Amsterdam/Philadelphia: John Benjamins.

- (2000). The revenge of the uneven trochee: Latin main stress, metrical constituency, stressrelated phenomena and OT. In Analogy and Markedness: Principles of Change in Phonology and Morphology. Aditi Lahiri (ed.), 332-352. Berlin/New York: Mouton de Gruyter.

- (2003). The emergence of quantity-sensitivity in Latin: Secondary stress, Iambic Shortening, and theoretical implications for "mixed" stress sytems. In Optimality Theory and Language Change, D. Eric Holt (ed.), 229-247. Dordrecht: Kluwer.

Kager, René. (1997). Rhythmic vowel deletion in Optimality Theory. In Derivations and Constraints in Phonology, Iggy Roca (ed.), 463-499. Oxford: Clarendon.

- (1999). Optimality Theory. Cambridge: Cambridge University Press.

Keil, Heinrich (1857-1880). Grammatici latini. Vol. 1-7. Leipzig: Teubner.

Kiparsky, Paul (1998). Paradigm effects and opacity. Ms.

Lahiri, Aditi, Tomas Riad and Haike Jacobs. (1999). Diachronic prosody. In Word Prosodic Systems in the Languages of Europe, Harry van der Hulst (ed.), 335-422. Berlin/New York: Mouton de Gruyter.

Lindsay, Wallace (1894 [1963]). The Latin Language. 2nd edition. New York/London: Hafner.

- (1922). Early Latin Verse. Oxford: Clarendon Press.

McCarthy, John (1997). Sympathy and phonological opacity. Ms.

McCarthy, John and Alan Prince. (1993). Generalized alignment. In Yearbook of Morphology 1993, Geert Booij and Jaap van Marle (eds.), 79-153. Dordrecht: Kluwer.

Mester, Ralf-Armin (1994). The quantitative trochee in Latin. Natural Language and Linguistic Theory 12: 1-61.

Niedermann, Max (1931). Phonétique historique du latin. Paris: Klincksieck.

Prince, Alan and Paul Smolensky. (1993). Optimality Theory: Constraint interaction in generative grammar. Technical Report 2, Rutgers University. 
Rubach, Jerzy (1997). Extrasyllabic consonants in Polish: Derivational Optimality Theory. In Derivations and Constraints in Phonology, Iggy Roca (ed.), 551-581. Oxford: Clarendon Press.

Thierfelder, Andreas (1928). Iktierungen des Typus facilius. Appendix to Fraenkel (1928). 